\title{
Ignaz Venetz
}

1788-1859

\author{
Von Heinz Balmer*
}

\section{Der junge Venetz}

Die Venetz waren um 1400 aus Venedig ins Saastal eingewandert. Sie gelangten zu Ämtern und stellten Priester. Das Geschlecht verzweigte sich in Stalden, erreichte in Visp das Rhonetal und drang aufwärts nach Mörel, abwärts nach Sitten vor.

Ignaz Venetz wurde am 21.März 1788 in Visperterminen geboren. Das Stammhaus seiner Familie stand an der neuen Brücke bei Stalden. Seine Eltern waren Peter Ignaz Venetz und Anna Maria Stoffel. Als Schreiner und Kunsttischler, Müller und Bäcker fand der Vater nur karge Einkünfte. Trotzdem schickte er den begabten Sohn in das Kollegium Brig. Es war von Jesuiten geleitet. Der Knabe fügte sich gut ein, lebte auf an Mathematik und Naturwissenschaften und ging den vorgezeichneten Weg ins bischöfliche Priesterseminar. Die Wogen der Zeit rissen ihn los. Die Franzosen hatten das Wallis besetzt und zum Departement Simplon gestempelt. Die Pläne und Bauten ihrer Ingenieure zogen Venetz unwiderstehlich an. Er trat in ihr Korps für Brücken- und Wegebau und gab dadurch seinem Leben die Richtung. 1815 drangen die Österreicher ins Tal und stellten den jungen Walliser Ingenieur in ihr Heer. Er wurde Artillerieoffizier und arbeitete mit einer Kompanie Kroaten an den Festungswerken von St-Maurice. Als die Österreicher abzogen, begleitete er sie bis Domodossola. Dort erbat er den Abschied und kehrte um. Was er unter fremder Besatzung gelernt hatte, verwendete er fortan im Dienste der Heimat.

Er wurde Walliser Kantonsingenieur und blieb es 20 Jahre. Mit dem jährlichen Gehalt von 1200 Franken hatte er eine wachsende Familie zu ernähren. Seine Frau Maria Josepha, eine Tochter des Architekten JeanJoseph Andenmatten, schenkte ihm sieben Kinder: Eugène, Ruffina, Ludwig, Louise, Joséphine oder Josette, Franz und Grégoire. Die meisten

* Die Anregung, mich mit Venetz zu befassen, verdanke ich Herrn JosePH Bürcher in Visp, der mir eine handschriftliche Studie schenkte, die sich vor allem auf HaLlenbarter stützte, aber weitere Hinweise enthielt. Besonders viel bot mir die Arbeit von IGNACE MARIÉTAN. 
starben jung und unverheiratet. Am Leben blieben Franz und zwei Töchter. 1837 trat Venetz in waadtländische Dienste, blieb aber dem Wallis als Berater nahe.

\section{Arbeiten am Giétroz-Gletscher}

Der Giétroz-Gletscher liegt oben im Bagnes-Tal rechts an den Hängen der Berge Ruinette und Mont Blanc de Ceilon. Er ist $41 / 2 \mathrm{~km}$ lang und endet über einer $700 \mathrm{~m}$ hohen Felswand. Ein Wildbach hat sich unter dem Firn einen Gang gehöhlt und stürzt in stiebendem Fall zur Drance herab. Auch links, unter Mauvoisin, gehen steile Felsen nieder. Die Drance gewinnt den Ausfluß durch eine Schlucht, die man auf hoher Brücke überschreitet. Unten breiten sich die Alpweiden von Bonatchesse.

1805 hatte Salinendirektor Jean de Charpentier von Bex, 1811 Venetz den wilden Ort besucht. Am Fuße des Wasserfalls hatten sie zerstreute Eisblöcke gesehen, die oben vom Gletscher abgebrochen waren. Die kalten Jahre 1811 bis 1818 schütteten viel Schnee aus, und die Eisströme wuchsen. Die Stirn des Giétroz-Gletschers stieß über die Felswand hinaus ins Leere vor. Große Eismassen lösten sich und krachten in die Enge herab. Lawinenstürze schweißten die Bruchstücke zu einem Wall zusammen, der das Tal abriegelte. Die Drance grub sich darunter einen Tunnel. Zu Frühlingsanfang 1817 wurde der Durchlaß verstopft, und es begann sich ein See zu stauen. Doch rechtzeitig wurde das Loch wieder frei, und es gab keinen Schaden.

Als anfangs April 1818 Bauern auf ihre Alpen von Bonatchesse stiegen, gewahrten sie, daß die Drance nur als spärliches Rinnsal sickerte. Sie klommen zur Kapelle von Mauvoisin empor und erblickten nun unter sich den Gletscherwall und dahinter einen neuen See. Es wurde ins Tal gemeldet. Aber erst am 8. Mai beauftragte der Staatsrat zwei Abgeordnete und Ingenieur Venetz mit der Untersuchung. Als Venetz mit seinen Begleitern am 12. Mai ankam, erschrak er. Der See war über $2 \mathrm{~km}$ lang, $200 \mathrm{~m}$ breit und $60 \mathrm{~m}$ tief, und das Wasser stieg täglich um ein Meter. Der Wall hatte Kegelform; unter dem Felshang des Giétroz betrug seine Höhe 146 m, unter dem von Mauvoisin $93 \mathrm{~m}$. Ein Pfropfen aus Eis und Schnee verstopfte den Tunnel. Wenn er unter dem Druck des Seewassers gewichen wäre, hätte das Tal eine Überflutung erlitten. Während der Anblick des Riegels seine Gefährten beruhigte, erkannte Venetz die wachsende Gefahr und die mögliche Rettung. Man mußte dort, wo der Wall am niedrigsten war, einen Einschnitt, 
einen Korridor, eine Galerie heraushauen, damit das Wasser von einem gewissen Stande an durch diese Kerbe abfloß und nicht weiter anstieg. Die Arbeit war ein Wagnis. Von rechts drohten Eisstürze, von links Lawinen und Steinschlag. Dennoch begann Venetz schon am 13. Mai mit einer Mannschaft, den Plan auszuführen. Mit Äxten hieb man mitten auf dem Eiswall einen Schacht, warf die Schollen in Körbe und zog sie auf Schlitten seitab. Dann drang man gleichzeitig seewärts und talabwärts vor, so daß je zwei Arbeitsgruppen abwechseln konnten. Der Gang wurde $195 \mathrm{~m}$ lang, 1,30 m breit und fast $2 \mathrm{~m}$ tief. Der Seespiegel lag anfangs noch weit unterhalb. Die Leute übernachteten in Bonatchesse. Als aber vom 14. Mai abends bis zum folgenden Mittag $60 \mathrm{~cm}$ Neuschnee fielen, blieben von 32 Arbeitern nur fünf. Ein erhöhtes Taggeld rief viele zurück. Gerüchte verbreiteten Schrecken. Dekan Philippe Bridel von Montreux besichtigte daher am 16. Mai den Schauplatz und ließ einen Bericht über den wahren Sachverhalt drucken. Am 18. Mai stürzte eine große -Eismasse herab. Zum Glück wurde niemand verletzt. Venetz mußte einige Italiener entlassen, da ihre Kleidung für die Kälte nicht genügte. Am 20. Mai wurde ein Ausschuß bestimmt, der an gegenseitig sichtbaren Punkten des Tales Scheiterhaufen errichten und je zwei Wächter dazustellen ließ. Bei Gefahr sollten diese Zeichen entflammt und die Sturmglocken geläutet werden. Am 26. Mai begaben sich Behördemitglieder zum Tatort. In Bonatchesse begegneten sie Charpentier. (Dessen Rapport über den See an den Staatsrat wurde in der Lausanner Zeitung teilweise abgedruckt, wie aus seinem Briefe an Meisner vom 17.Juni 1818 hervorgeht.) Man erkannte, daß die Arbeit eile. Wasser, das in die Schuhe eindrang, erschwerte das Stehen im Stollen gegen den See zu. Tags darauf stiegen mächtige Eisblöcke an die Seeoberfläche; sie hatten sich unter Getöse vom Riegel abgelöst. Wellen schwappten in den Einschnitt. Venetz fürchtete, der Tunnel in der Tiefe öffne sich und der See fließe aus; doch es geschah nicht.

Am 29. Mai loderten die Warnfeuer auf. Ein Irrtum hatte sie entfacht. Zufällig hatte in der Nähe eines Postens ein Feuer gebrannt und den Alarm ausgelöst. Am folgenden Tag hoben sich weitere Eisschollen an die Seefläche. Der Korridor wurde am 4. Juni vollendet. Da das Wasser noch nicht bis zu ihm gestiegen war, glich man ihn aus und vertiefte ihn. In der Nacht zum 11. Juni trennte sich eine neue Eismasse ab und tauchte an der Wasserfläche auf. Endlich begann am 13. Juni abends zehn Uhr der Abfluß. Bald strömten schwimmende Schollen in den Einschnitt und versperrten ihn. Ein beherzter Arbeiter, Jacob Aberlin, lockerte unter Lebensgefahr den hem- 
menden Block. Das Rauschen des Wassers, das sich vom Ende der Galerie in die Tiefe warf, dröhnte durch die Nacht zum Wachtposten auf der Brücke von Mauvoisin. Erschrocken legte er den Zunder an, und sein verfrühtes Signal pflanzte sich bis Martigny fort. Die Talbevölkerung flüchtete sich auf die Höhen. Doch die Schranke hielt stand.

Es erging Befehl, die Brandstöße zum drittenmal herzustellen. Man war dessen müde und gehorchte dem Aufruf nur im unteren, nicht aber im mittleren Talabschnitt. Venetz blieb sorgenvoll und wachsam. «Er ist kostbar für uns, ebenso unermüdlich wie scharfsinnig », schrieb ein Gast. Was Venetz beunruhigte, war die Gewalt, mit der das abfließende Wasser den Eisriegel erschütterte. Es vertiefte den Gang und schnitt am untern Ende mit niederschießendem Strahle ein Becken hinein. Bis zum Abend des 15.Juni war der Seespiegel um mehr als $3 \mathrm{~m}$ gesunken. Jedoch Venetz sah, wie das Wasser sägte, nagte, höhlte. Er verbrachte die folgende Nacht wachend auf dem Gletscher. Wieder verstopfte ein Eisstück den Durchpaß. Ein deutscher Arbeiter ließ sich mit dem Spaten mutig hinab, riß die Strömung frei und konnte sich retten. Am Morgen hatte die Absenkung $9 \mathrm{~m}$ erreicht. Jetzt aber bahnte sich das Wasser einen Durchgang unter dem Eiswall. Man hörte es darin krachen und bemerkte, wie das Wasser darunter hervorzuquellen begann. Das Unglück nahte. Am Nachmittag eilte Venetz mit seinen Begleitern talabwärts, um die Leute zu warnen. Doch schon um halb fünf Uhr verkündete ein furchtbarer Knall, daß der See ausbrach. In weniger als einer halben Stunde war er entleert. In der Schlucht von Mauvoisin stieg das Wasser um $30 \mathrm{~m}$ und riß die Brücke fort. Es ergoß sich über die Ebene von Bonatchesse, deckte sie mit Geröll und spülte 42 Gebäude weg. Auf der nächsten Alp wurden ein Mann und 30 Hütten fortgerissen, in Fionnay 57 Gebäude. Venetz befand sich etwas weiter unten am Talhang. Er sah, wie Schlamm, Geröll und Bäume sich als schwarze Masse vorüberwälzten. Die 31 Hütten der Alp Granges Neuves wurden fortgeschwemmt, in Lourtier 15 Häuser und 37 Scheunen, in Champsec zwei alte Frauen, 13 Häuser, 45 Scheunen, 15 Kühe. In 40 Minuten erreichte die Flut Châble, tötete einen Knaben und ein Mädchen, in Sembrancher zwei Männer, zwei Frauen, ein Kind. Von Châble bis Martigny brauchte der Strom 50 Minuten; dort teilte er sich in Arme und erreichte die Rhone an mehreren Stellen. Da sie niedrig floß, vermochte ihr Bett den Zulauf zu fassen. Schwimmende Trümmer bedeckten den Genfersee.

Das ganze Tal der Drance war furchtbar verwüstet. Das Fehlen der Warnfeuer im mittleren Abschnitt wurde für Martigny zum Verhängnis. Erst 
um Viertel vor sechs Uhr hatten die Wächter in Chemin, auf dem Sporn über Martigny, ihren Holzstoß angezündet. Eine Viertelstunde später kam die Flut und forderte 34 Todesopfer. Die Brücken und Holzhäuser wurden fortgerissen, die Steinhäuser bis zum ersten Stock mit Schlamm gefüllt.

Die Schweiz nahm an dem Unglück des Tales Anteil. Die Tat von Venetz wurde beachtet. Gaben strömten herbei.

Nun galt es, für die Zukunft vorzubeugen. Am 9. Juli legte Venetz einen Plan zur Eindämmung und Geradelegung des Unterlaufs der Drance vor. Der Eisriegel konnte sich wieder schließen, die Gefahr wiederkehren. Am 24. Juli begleitete Venetz Hans Conrad Escher von Der Linth zum Giétroz-Gletscher. Die beiden modellierten ein Relief des Tales ${ }^{1}$. Ende Juli tagte die Schweizerische Naturforschende Gesellschaft in Lausanne. Venetz ging hin. Dekan Bridel und Escher berichteten. Escher erklärte, wenn der Einschnitt nicht gegraben worden wäre, so hätte die Wassermasse sich noch verdreifacht. Das Unglück wäre einen Monat später eingetreten, und weil die Rhone da ohnehin Hochwasser führte, wäre das ganze untere Rhonetal überschwemmt worden. Ein einziges Mittel vermöchte die Bedrohung abzuwenden: ein Stollen durch die Felsen von Mauvoisin, der auf einer $640 \mathrm{~m}$ langen Strecke die Drance unterirdisch leiten würde und am Ein- und Ausgang von den Eisstürzen nicht verschüttet werden könnte.

Nachdem Venetz diesen Plan näher geprüft hatte, schrieb er im Juli 1819 an Escher, die Länge müßte $800 \mathrm{~m}$ betragen. Zugleich bat er die Walliser Regierung, einen Ausschuß zur Begutachtung der vorzunehmenden Arbeiten zu ernennen. Dies geschah. Escher, Charpentier und Physikprofessor Friedrich Treghsel von Bern wurden beauftragt und legten im Sommer 1820 in Genf klaren, genauen Bescheid vor. Venetz wurde als «ebenso erfahrener wie mutiger und ausdauernder Ingenieur» gelobt. Der Ausschuß riet vom allzu schwierigen Stollenbau ab und befürwortete eine aufmerksame Überwachung des Gletschers. Sobald ein See sich bilde, solle frühzeitig ein Eisdurchstich bereitet werden.

Venetz aber erfand ein anderes, unerwartet neues Mittel. Die Gewalt, mit der das fließende Wasser sich in den Eisriegel geschnitten hatte, blieb ihm eingeprägt. Nun beschloß er, das Wasser einer benachbarten Quelle heran-

1 Mechaniker ANGelin in Bex, «ein sehr geschickter und kenntnisvoller Mann», unternahm damals oder bald nachher von Bex bis zum Gletscher Barometermessungen und Höhenberechnungen, die Charpentier am 12.September 1818 an Meisner in Bern zur Veröffentlichung im Naturwissenschaftlichen Anzeiger schickte. 
zuleiten und den Strahl auf das Eis wirken zu lassen. Die Regierung stimmte 1821 zu, und Venetz führte das Vorhaben in jenem Sommer aus. Um das Gletschertor offen zu halten, wollte er mit dem fallenden Wasserstrahl Stücke vom Eis abtrennen. Er faßte die Quelle La Liaz und leitete sie in Holzrinnen bis zum Gletscher. Aus zwei nebeneinander laufenden Rinnen sprühte das Wasser nieder; so wurde das Eis in Schichten abgesägt und fiel in den Fluß. Die Arbeiten wurden 1822 und 1823 fortgesetzt. Im kalten Sommer 1823 wurde die Gefahr besonders groß. Es war schwierig, die Gerüste mit den Rinnen auf dem spaltenreichen Eise zu verlegen. Ein Arbeiter wurde von einem Blocke mitgerissen und ertrank im Fluß. Venetz und zwei andere Männer stürzten in Spalten; sie wurden gerettet.

Das Unternehmen erhielt einen Gegner. Jean -Joseph Blanc, der Kaplan von Bagnes, veröffentlichte 1825 seine Einwände. Er schrieb, Venetz lasse Wasserstrahlen auf das Eis fallen, um es zu vernichten. Da die Flüssigkeit nur durch Reibung und Wärme angreifen könne, müsse die Wirkung fast Null sein. Die Gletscher seien ohnehin im Rückzug begriffen. Nutzlos sei ein Viertel der Hilfsspenden verschwendet worden. Venetz antwortete mit einer «Verteidigung der Arbeiten am Giétroz-Gletscher». Ruhig erklärt er: «Wäre der Gletscherriegel im Zustand von 1818 geblieben, so wäre es überflüssig, dagegen vorzugehen. Aber das vom obern Gletscher herabfallende Eis hat sich so sehr vermehrt, daß anfangs Juni 1822 die Drance auf einer Länge von $430 \mathrm{~m}$ bedeckt war. Seit dem Beginn der Arbeiten bis zum Oktober 1824 ist der Wall um die Hälfte verkleinert worden.»

Ein Regierungsausschuß hatte 1822 berichtet, wie schwach und kraftlos die Wasserstrahlen auch scheinen möchten, so hätten sie doch Breschen geschlagen, und man könne zusehen, wie sie Eisplatten absägten. - Es stimmte, daß die Gletscher seit 1820 zurückgingen. Venetz bat am Schluß seiner Verteidigung um eine Prüfung durch eine Abordnung der Schweizerischen Naturforschenden Gesellschaft. Sie wurde bei der Jahresversammlung von 1825 in Solothurn ernannt und bestand aus drei Genfern: dem Kantonsingenieur Guillaume-Henri Dufour (*1787), dem Geologieprofessor Louis Negker (*1786) und dem Botaniker Augustin-Pyramus de CAndolle (*1778). Sie berichteten ein Jahr darauf, der Gedanke, mit fließendem Wasser eine Eismasse in Stücke zu schneiden, sei durch Einfachheit und Sparsamkeit der Mittel ausgezeichnet. Das Ziel sei nicht, den Gletscher zu schmelzen, sondern Stücke davon abzutrennen.

Als sich die Naturforscher im Juli 1829 auf dem Großen St. Bernhard versammelten, sprach Venetz über den Fortgang der Arbeiten und über einen 
Entwurf, den Lawinen vorzubeugen, die vom Berg von Mauvoisin herabstürzten.

Im ganzen hatte das Unternommene Erfolg. Die Regierung, die Talbevölkerung und schließlich auch Blanc waren zufrieden. Venetz legte 1843 noch einmal Rechenschaft ab. Man setzte die Bemühungen bis 1884 fort. Der Rückzug des Gletschers erlaubte das Aufhören. Heute füllt ein Stausee jenen Talabschluß, und die Gefahr ist dadurch gebannt.

\section{Weitere Arbeiten als Walliser Kantonsingenieur}

a) Als Gutachter in Randa (1819)

Randa liegt im Tal von Zermatt. Dem Dorfe schräg gegenüber steigen im Westen nackte Felsen hoch empor, und darüber erscheint die Stirn des vom Weißhorn herabwallenden Biesgletschers, von dem sich zuweilen Stücke ablösen und gegen Randa fallen. Dies geschah 1636, 1737 und wieder am 27.Dezember 1819. Das Dorf wurde diesmal nicht getroffen; aber der Luftdruck fegte die Kirchturmspitze hinweg, verwüstete 17 Häuser, 72 Scheunen und Ställe. Zwei Menschen wurden getötet, große Lärchen entwurzelt. Man bat Venetz um Rat. Er beschrieb den Vorgang und konnte nur empfehlen, das Dorf weiter talaufwärts zu verlegen.

b) Am Märjelensee (besonders 1828)

An der linken, östlichen Flanke des Aletschgletschers mündet zwischen Eggishorn und Strahlhorn ein Tälchen gegen diesen Gletscher zu. Da er es abriegelt, sammelt sich darin Wasser und bildet den Märjelensee. Dessen Wachstum war begrenzt. Wenn er bis zur Höhe des hintern Abschlusses voll war, entsprang ihm dort ein Bach und ergoß sich nach der andern Seite ins Fieschertal. Alle paar Jahre aber ereignete es sich, daß der vordere Riegel plötzlich unter sich Durchlaß gewährte. Dann leerte sich der See binnen Tagen oder Stunden. Er flutete durch das Bett des Aletschgletschers und durch das wilde Tal der an dessen Spitze entspringenden Massa. In deren Schlucht entstand kein Schaden, wohl aber bei der Ausmündung ins Rhonetal, wenn das überschwemmende Wasser hervorbrach und der Strom der Ebene sonst schon Hochwasser führte.

Venetz sollte die Lage untersuchen und die Gefahr dämpfen. 1820, 1827 und 1828 erstattete er Bericht. Er schlug vor, im Hintergrund des Tälchens 
einen Einschnitt in den Boden zu graben, damit das Wasser schon gegen das Fieschertal abzufließen beginne, bevor der See hoch anschwelle. Die Fieschertaler malten sich Schrecknisse aus und erhoben zähen Widerspruch. Da ihre Einwürfe der Begründung entbehrten, bewilligte der Staat 1828 das nötige Geld, und der Graben wurde ausgehoben. Er war $80 \mathrm{~m}$ lang und 3,80 m tief. Da er die Gefahr nicht genügend bannte, wurde 1890 bis 1894. tiefer unten ein Tunnel hindurchgestochen, der 1896 Dienste leistete. Seither aber ist der See zurückgegangen, weil auch der Aletschgletscher abgenommen hat, und die Drohung ist beseitigt.

\section{c) Am Mattmarksee (besonders 1834)}

Hinten im Saastal erreichten von links her zwei Gletscher den Talgrund, der Schwarzenberggletscher und weiter talauswärts der mächtige Allalin. Als dieser seit 1815 stark wuchs, stieß er 1819 an die gegenüberliegende Talwand, bildete einen Riegel und staute einen See auf, der eine Stunde Umfang gewann. Das Wasser höhlte unter dem Eis einen Tunnel und floß ab. Es kam vor, da $ß$ sich im Winter der Durchgang verstopfte, und wenn der Pfropfen sich löste, wurden die Täler von Saas und Visp verwüstet. Als Venetz 1811 jene Talgegend von Mattmark besuchte, waren die Gletscher noch harmlos. Als er 1818 und 1821 zurückkehrte, waren sie stark vorgestoßen.

Ein mächtiger Serpentin-Findling, Blauenstein genannt, lag hinten im Tale. Venetz maß ihn aus. Er war $22 \mathrm{~m}$ lang, 18 breit und 20 hoch und hatte $8000 \mathrm{~m}^{3}$ Inhalt. Alte Saaser erinnerten sich, wie einst ihre Väter erzählten, sie hätten den Block noch auf dem Rücken des Schwarzenberggletschers gesehen. 1818 berührte dessen Zunge den gewaltigen Stein wieder und stieß ihn vorwärts.

Am 20. September 1833 schickten die vier Gemeinden des Saastals einen Eilboten zu Venetz. Er sollte sofort den hohen Stand des Mattmarksees besichtigen. Man wußte, daß dieser 1633, 1680 und 1772 den Eiswall durchbrochen und den Talboden bis Saas-Grund mit Schlamm, Sand und Steinen überdeckt hatte. Bereits am 21. September beantragte Venetz bei der Regierung dringende Vorbeugungsmaßnahmen. Die Unterstützung wurde bewilligt. 1834 ließ Venetz einen Einschnitt auf dem Eis des Allalingletschers graben und senkte so den Seespiegel um fast $2 \mathrm{~m}$. Das Wasser floß fortan jahrelang durch diese Kerbe. Der Fall lag hier günstiger als beim GiétrozGletscher, weil der Riegel aus festem Eis und nicht aus einem Gemisch von Schnee und Eis bestand. Bis 1848 hatte der See um ein Drittel abgenommen. 


\section{d) Die Rhone-Eindämmung}

Einst breitete die Rhone ihr Wasser frei auf der Ebene aus. Die Dörfer suchten sich auf den Schuttkegeln zu sichern; Überschwemmungen waren zahlreich, obschon man da und dort Dämme aufwarf. Venetz hatte sich mit der Rhone zu befassen. Man wollte von St-Maurice bis zur Mündung in den Genfersee gegen den Strom kämpfen. Da er auf dieser Strecke die Grenze zwischen Waadt und Wallis bildete, trafen sich Abgeordnete beider Kantone 1825 zu einer ersten Sitzung in Bex, darunter die beiden Kantonsingenieure, für das Wallis Venetz, für die Waadt Adrien Pichard (1790-1841). Man fand sich 1829 wieder in St-Maurice zusammen. Inzwischen hatten Venetz und Pichard einen Plan des Flußlaufs aufgenommen und ihren Vorschlag eingetragen. Während die Rhone bisher breit dahinlief, wollten sie deren Seitenarme abschneiden, das Wasser in ein einziges Bett sammeln und es eng halten, um die Durchflußgeschwindigkeit zu steigern. Die Gemeinden lehnten den Entwurf ab, da sie die Kosten scheuten. Erst, nachdem die Rhone 1834 wieder über die Ufer gequollen war, schickten Wallis und Waadt ihre Vertreter im April 1836 zu einer dritten Zusammenkunft nach Devens, wo Charpentier einen Bericht verlas. Der Plan von 1829 wurde mit wichtigen Abänderungen angenommen. Die von Venetz vorgeschlagenen Strebepfeiler wurden nur auf der Walliser Seite bewilligt.

Man erkannte im Wallis, daß der Kampf sich auch flußaufwärts bis Brig erstrecken müsse. Einfache seitliche Dämme genügten nicht, weil das Wasser sie annagte. Es mußte ein Verfahren ersonnen werden, das sie festigte. Venetz besaß unterhalb Martigny ein Stück Land an der Rhone. An diesem Versuchsfeld baute er einen Damm und sicherte ihn durch Strebepfeiler senkrecht zur Flußrichtung und durch gemauerte Querdämme oder Traversen, die sich alle $30 \mathrm{~m}$ folgten. Sie zähmten und lähmten die fortreißende Kraft.

Erst nach Venetz' Tode, nach den schweren Überflutungen von 1860, wurde die Eindeichung der Rhone mit diesem Verfahren der Querdämme allgemein befolgt. Sein Sohn Franz erwarb sich das Verdienst der Durchführung. Sie wurde ein erhebendes Zeugnis des Gemeinsinns. Der französische Geograph Jean Brunhes schrieb in seiner Géographie humaine (Paris 1910, S.793): «Die wundervollen Arbeiten der Rhoneeindämmung sind eines der vorbildlichen Werke, die der Schweiz im 19. Jahrhundert zur Ehre gereichen.»

Leider hatte Venetz nicht alles vorausgesehen. Das Gewicht der Kieselsteine, die ein Fluß bewegen kann, nimmt mit der 6. Potenz der Geschwin- 
digkeit zu. Eine nur geringe Verlangsamung reicht hin, daß der Sand nicht mehr mit fortgespült wird, sondern liegenbleibt. Dadurch wird das Flußbett über die Ebene gehoben. Kaum kann man die Dämme mehr halten, kaum die Zuflüsse einleiten. Der Grundwasserspiegel hebt sich; die Ebene verwandelt sich in Sumpf und erfordert Entwässerungsgräben. Als diese Folgen eintraten, mußte man die Querdämme wieder entfernen. Sie hatten nicht dauernd, aber vorübergehend geholfen.

\section{Venetz als Ingenieur des Kantons Waadt (1837-1855)}

Von der Dämmung der Rhone schritt Venetz weiter zur Eindeichung der Bucht von Clarens am Genfersee.

Seit fast 150 Jahren bildete diese Bucht ein Ärgernis. Die Ufergegend und die große Straße wurden immer wieder überschwemmt und mit Kies verschüttet. 1823 begann man, Dämme aufzuwerfen; 1825 wurden sie von der Flut wieder vernichtet. 1833 schrieb der Kanton Waadt einen Wettbewerb aus. Als einziger Unternehmer meldete sich Venetz. Er erhielt den Auftrag und übernahm damit eine Last, die ihn bis ins Alter drücken sollte.

Diese Arbeit beanspruchte ihn mehr und mehr. Auf Ende 1837 trat er als Ingenieur des Kantons Wallis zurück und wechselte über in die Dienste der Waadt. Sein Nachfolger im Wallis wurde de Torrenté. Doch blieb Venetz mit der Heimat verbunden. 1837/38 war er Großrat des Bezirkes Visp.

Zuerst hatte Venetz in der Bucht von Clarens Erfolg. Seine Anlagen zwangen das Wasser, Schwebestoffe zwischen Deiche abzulagern. Sobald eine Erdbedeckung vorhanden war, pflanzte er Reben. Aber zwei Hochwasser verursachten 1840 großen Schaden. Der Staat half, und Venetz verstärkte die Dämme. 1845 gab es neues Unheil, und Ende August 1846 vernichtete ein überaus heftiges Gewitter den größten Teil der Werke. Die Mittel von Venetz waren erschöpft, und er bat um Enthebung von dieser Pflicht. Zwölf Jahre der Anstrengung hatten ihn seiner letzten Barschaft beraubt und ließen ihm Schulden zurück. Die Regierung übernahm die Dammbauten, die er bis dahin auf eigene Rechnung betrieben hatte. Ein Beschluß des Großen Rates vom 19. Mai 1847 versprach ihm eine Entschädigung für das von ihm erbaute Haus und für den verschont gebliebenen Teil des angelegten Weinlandes, wovon noch sieben Posen (zu 50000 Quadratfuß) in schönstem Ertrag standen. 
Charpentier bat am 15. März 1847 seinen jungen Freund KARL FrIEdrich Meissner, Botanikprofessor in Basel, beim reichen Geologen Peter Merian sein möglichstes zu tun, daß er Venetz sogleich wenigstens tausend Franken borge. «Die Herren risquiren durchaus nichts und reißen den armen guten Kerl aus der größten Verlegenheit.» Wirklich wurde Venetz ein Darlehen gewährt; doch war es ihm zunächst unmöglich, auch nur die Zinsen zu vergüten. Als Meißner im Februar 1849 bei Charpentier Nachfrage hielt, antwortete dieser umgehend: «Da nun auch unsere Regirung von der Dauergelenkparalysie ... stark befallen worden ist, so ist ihm bis heute jene Entschädigung noch nicht ausgezahlt worden, und dieß ist die einzige wahre Ursache warum er sich bis jetzt seiner Schuld noch nicht hat entledigen ja nicht einmal die Interessen abtragen können. Dieß entschuldigt ihn aber nicht, daß er nicht schon längst deßhalb an Herrn Peter Merian geschrieben, ihm die Ursache jener Verzögerung gehörig aus einander gesetzt und um Gedult und Nachsicht gebeten hat, was er nun gewiß sogleich thun wird, und bis jetzt nur aus einer kindischen Verlegenheit und aus Scham ... unterlassen hat. Uebrigens kannst Du den Herrn Staatsrath Merian versichern daß weder das Kapital noch die Interessen gefährdet sind, indem nicht allein die Grundstücke die er bei Martigny und bei Vispach besitzt, hauptsächlich aber die Rechtlichkeit und das Ehrgefühl was nicht allein ihn sondern auch seinen Sohn, Frau und 2 Töchter wirklich auf eine seltene Weise auszeichnen, hinlängliche Sicherheit für jene Schuld gewähren.» Venetz hatte die Regierung kurz zuvor um baldige Auszahlung des versprochenen Schadenersatzes gebeten. Er erlebte die Begleichung nicht mehr. Seine Erben wurden 1868 mit 4000 Franken abgefunden.

Für Merian war Venetz kein Unbekannter. Gemeinsam bereiteten sie die Entsumpfung der Orbe-Ebene vor, und auf Grund ihres Gutachtens konnte diese Arbeit 1854 beginnen.

Die Absenkung der Juragewässer und die Austrocknung der Sümpfe der Orbe und Broye beschäftigten Venetz während seiner Dienste in der Waadt. Schon 1843 hatte man ihn beauftragt, den günstigsten Lauf der Broye zu bestimmen. Sein Plan wurde 1849 eingereicht, aber nicht ausgeführt.

Venetz dachte auch darüber nach, wie man den Schlammgehalt der Flüsse zur Ablagerung an einem gewünschten Orte zwingen und damit sumpfigen Boden künstlich erhöhen könnte. An der Rhone beobachtete er, daß der Schlammgehalt mit der Tiefe der Wasserschicht zunahm. Er baute daher eine Schleuse mit einer Art Schornstein, der auf Pfählen ruhte und tief hinabtauchte, so daß nur Wasser vom Grunde eindrang. Eine erste Schleuse 
dieser Art wurde 1852 am Waadtländer Ufer der Rhone beim Genfersee gebaut. Am Jahresende maß Venetz eine Ablagerung von 1,60 m Schlamm. Der Erfolg überzeugte, so daß noch mehrere solche Schleusen mit Kamin längs der Rhone im Kanton Waadt aufgestellt wurden, um Niederungen für den Anbau zu gewinnen. Die Erfindung war von Venetz im August 1851 in der Bibliothèque universelle erläutert worden. Die Abhandlung betraf Deiche, Schleusen mit Kamin für künstliche Bodenerhöhung und die Grundsätze bei der Geradelegung von Flußläufen mit besonderer Beziehung auf die Orbe und Broye und auf die Trockenlegung der angrenzenden Sümpfe.

1855 verließ Venetz mit 67 Jahren die waadtländischen Dienste und kehrte nach Sitten zurück.

\section{Venetz als Begründer der Glazialtheorie}

Tausendfach ist heute die Wahrheit bestätigt, daß im Quartär die Gletscher eine riesige Ausdehnung hatten, Moränen und Findlinge trugen, bei der Tal- und Seebildung halfen.

Anders war es in den Jahrzehnten vor und nach 1800. Beeinflußt vom Glauben an die biblische Sintflut, hielt man das Wasser für das Beförderungsmittel der Findlinge. Nur Jean -André Deluc meinte, Gaszerknallungen hätten diese Steine weggeschleudert. Die andern Forscher überlegten, wo die fortspülenden Wasserfluten hervorgebrochen sein könnten. Horace-BÉnédict de SAussure dachte an Höhlungen der Alpen, die sich bei einer Erschütterung geöffnet hätten, HANs Conrad Escher von DER Linth an ruckhaft ausgeflossene Bergseen, Elie de BEAumont an plötzlich geschmolzene Gletscher. LEOPOLD voN BucH stellte sich Schlammströme vor.

John Playfair in Edinburg sprach 1815 als erster aus, die Gletscher könnten die Findlingsblöcke gebracht haben. Da er es zuwenig begründete, verhallte es ungehört.

Im selben Jahre wurde in Genf die Schweizerische Naturforschende Gesellschaft gegründet. 1816 hielt sie ihre zweite Tagung in Bern. Venetz wurde Mitglied und erläuterte in einem Vortrag, wie Körper, die in Spalten eines Gletschers gefallen sind, später weiter unten wieder an dessen Oberfläche erscheinen. 1817 versammelte man sich in Zürich. Hier wurde das Vorrücken der Gletscher erwähnt und gefragt, ob es stimme, daß seit einigen Jahren das Hochalpenklima kälter und strenger geworden sei. Gerne hätte man über die Gründe des Gletscherwachstums Näheres erfahren. Der ber- 
nische Oberförster KarL Kasthofer lieferte eine Darlegung ab. Daraufhin stellte die Gesellschaft 1820 eine Preisaufgabe über die Veränderungen der Temperatur in den Schweizer Alpen. Man wollte Genaues über den Stand der Gletscher, der Alpweiden und Wälder vernehmen. Der einzige, der 1821 eine Antwort niederschrieb, war Ignaz Venetz. Er glaubte nicht an die Sintflut. Sein Beruf hatte ihn oft zu Gletschern geführt. 1811 war er in Mattmark, 1815 hinter Zermatt beim Gorner- und Z'Mutt-Gletscher, 1817 am Simplon gewesen. Eindrücklich hatte er die Wucht des Giétroz-Gletschers erlebt.

In seinen Beschäftigungen und Sorgen hielt er sich Atem und Blick für die Naturforschung frei. Er durchschritt weite Hochalpengebiete im Wallis und Mont-Blanc-Gebiet, um seine Gedanken zu prüfen.

Man besitzt zwar - wie er darlegte - keine Thermometermessungen über Jahrhunderte hinweg, kann aber aus andern Beobachtungen auf den frühern Zustand der Temperatur schließen. Die Verbesserung der Alpweiden und der Rückgang des Waldes freilich haben andere Ursachen und geben nicht Aufschluß. Die Nachricht von Bergübergängen aber, die einst von Gletschern versperrt waren und jetzt geöffnet sind, gibt einen Hinweis. Nichts belehrt uns über die Temperatur früherer Zeiten besser als die Zeugnisse des Vorrückens oder Schwindens der Gletscher, da diese mit der Höhe der Schneegrenze schwanken. Wie riesige Thermometer stoßen sie in kalten Epochen vor und ziehen sich in warmen zurück.

Aus neuerer Zeit finden sich Beweise für ein Vorrücken der Gletscher. Eine Wasserleitung hatte am Col de la Forclaz (südlich Martigny) über ein Steinbrücklein geführt, das nun von einem Gletscher bedeckt war. Der Col de Fenêtre de Bagnes (zuhinterst im Val de Bagnes) ließ sich einst gut begehen, jetzt wegen eines Gletschers nicht mehr. Von einer Kapelle zwischen Fiesch und Grindelwald wird erzählt, daß ein vorrückender Gletscher sie zerstörte.

Zahlreicher aber sind die Spuren aus früheren Zeiten, die verraten, daß sich die Temperatur seither erhöht hat. Hier beschreibt Venetz die Moränen der Gletscher der Mont-Blanc-Gegend und dann des Wallis. Vier große, verzweigte Talschaften münden von Süden ins Rhonetal ein: bei Martigny das Bagnes-Tal mit dem Entremonttal und Val Ferret, bei Sitten das Val d'Hérens mit dem Val d'Hérémence, bei Siders das Val d'Anniviers mit dem Zinaltal, bei Visp das Matter- und Saastal. Venetz hatte alle begangen. Der Saleinaz-Gletscher im Val Ferret hatte in großen Moränen rechts und links deutliche Zeichen seiner frühern Ausdehnung hinterlassen. Die Gletscher im Bagnes-Tal waren ebenfalls von Moränen gesäumt. Der 
Lyrerose-Gletscher (am Südwestabfall der Ruinette, nur durch den Kamm des Col du Mont Rouge im Norden vom Giétroz-Gletscher getrennt) endete im Juni 1820 mit der Zunge $200 \mathrm{~m}$ oberhalb einer Moräne.

Von Brig aus hatte Venetz den Simplonpaß überstiegen und auf der Südseite, bei Eggen und Simplon Dorf, sechs Moränen beobachtet, die bei drei Vorstößen des vom Fletschhorn kommenden Roßbodengletschers abgelagert worden zu sein schienen. Venetz hielt sie in einer Zeichnung fest und schloß daraus, daß jener Gletscher einst von gigantischer Größe gewesen sei und bis zum Dorfe Simplon gereicht habe.

Er beschrieb auch die Moränen am Rawylpaß, der vom Wallis ins Simmental führt, die Moränen im Val d'Hérémence, im Val d'Anniviers bei St-Luc und im Zinaltal. Dort hatte er am 16. September 1821 vor dem Glacier de Durant oder Zinalgletscher vier Moränenwälle festgestellt. Der unterste, $100 \mathrm{~m}$ vor der Gletscherzunge, war von hohen Lärchen bewachsen; der zweite, weiter oben, trug erst halb so hohe Lärchen; der dritte war noch ohne Bewuchs, und der vierte lag $2 \mathrm{~m}$ vor dem Gletscher.

Während die Anzeichen für ein verhältnismäßig kleines Vorstreben der Gletscher aus neuerer Zeit stammten, waren seit der Vorzeit die Eismassen stark zurückgegangen.

Die Denkschrift von Venetz wurde durch einen Ausschuß von fünf Männern beurteilt. Es waren Charpentier, der Geograph und Geologe Johán Gottfried Ebel, Escher von der Linth, der Physiker und Astronom Johann Caspar Horner und der Genfer Physiker Marc-Auguste Pictet. Sie sprachen ihr den Preis von 300 Franken zu. Venetz las bei der Jahresversammlung vom Sommer 1822 in Bern aus der Abhandlung vor. Die Drucklegung beim Verlag Haller wurde vorgesehen. Doch Ende August bat Charpentier bei Meisner um die Rückgabe der Arbeit, da von Venetz noch Ergänzungen anzubringen seien. Dieser hatte inzwischen seine Moränenbeobachtungen erweitert; er setzte sie auch in den nächsten Jahren fort. Als die Schrift 1833 erschien, war sie reicher begründet als früher.

Venetz hatte nun auch das Oberwallis untersucht. Über dem linken Rande des Fieschergletschers gewahrte er eine große Moräne. Sie ließ ihn erkennen, daß der Eisstrom einst eine ungeheure Ausdehnung gehabt hatte. Am 22. September 1826 besuchte er die Grimsel. Hinter Obergestelen sah er Moränen eines nicht mehr vorhandenen Gletschers. Am selben Tage maß er die Schuttwälle des Rhonegletschers. Er unterschied deren neun. Auch im Eginental, das bei Ulrichen von links ins Rhonetal mündet, fand er Moränen.

Während er diese Gerölle bisher immer nur in der Nähe der Gletscher 
betrachtet hatte, begann ihn nun die Frage zu bewegen, bis wohin sie sich ausbreiteten. Er bemerkte, daß der Große Aletschgletscher bis Brig gekommen war. Auch entdeckte er die schönen Moränen von Ravoire (bei Martigny), von Plex (über Collonges) und von Monthey (gegenüber Bex) mit Granitblöcken vom Mont-Blanc. Weiter fand er die Spuren in Bex, in Aigle und dazwischen in St-Triphon, aber auch in Lausanne und im Mittelland bis zum Jura. Hatte er sich bisher noch in engeren Schranken bewegt und nicht Anstoß erregt, so erkannte er jetzt mit geschultem Auge und ausgeweitetem Sinn, daß die Blöcke vom Rhonegletscher bis in jene Ferne verfrachtet worden waren. Im Frühling 1829 eröffnete er Charpentier, das ganze Wallis sei einst von einem Gletscher erfüllt gewesen, der sich zwischen Genf und Solothurn bis zum Jura erstreckt habe. Charpentier war über den verrückten Einfall entrüstet.

Im Juli 1829 tagte die Schweizerische Naturforschende Gesellschaft auf dem Großen St. Bernhard. Von nah und fern kamen Gelehrte: von Lausanne Professor Daniel-Alexandre Chavannes, der Pfarrer und Zoologe, von Genf Professor Auguste de la Rive, der junge Physiker, von Neuenburg der naturforschende Kaufmann Louis Coulon, von Bern der Geologe Bernhard Studer, von Aarau Albrecht Rengger, Arzt, Staatsmann, Geologe, von Zürich PAUl Usteri, Arzt, Staatsmann, Botaniker, von Berlin der Geologe Leopold von Buch, von Paris der Astronom Alexis Bouvard. Auch Charpentier und Venetz waren anwesend, und Venetz griff zweimal zum Wort. Das eine war eine kurze Mitteilung über die gegenwärtigen Zustände am Giétroz-Gletscher, das andere aber ein Vortrag über die ehemalige Größe der Gletscher und ihre Rolle als Erzeuger der Moränen und Verbreiter der Findlinge. Das Sitzungsprotokoll vom 22. Juli meldet: «I. Venetz liest eine Denkschrift über die Ausdehnung, die, wie er glaubt, die Gletscher früher gehabt haben, und über ihren Rückzug in ihre heutigen Grenzen. Er erklärt die Mengen alpiner Gesteine, die an verschiedenen Stellen in den Alpen und im Jura zerstreut sind, ebenso wie in Nordeuropa, durch die Existenz ungeheurer Gletscher, die seither verschwunden sind, wobei diese Blöcke den Moränen angehörten. Er stützt diese Hypothese durch Aufzählung mehrerer Tatsachen, die er in der Umgebung der Gletscher der Walliser Alpen beobachtet hat.»

Man nahm ihn nicht ernst. Es schien unmöglich, daß die angesehensten Forscher wie Leopold von Buch, Elie de Beaumont und Alexander von Нuмвоцdт sich mit der Wassertheorie getäuscht hatten. Charpentier schämte sich für seinen Freund. Um ihn von seinem Irrtum zu befreien, be- 
gleitete er ihn in die Umgebung von Bex und Monthey und ließ sich im Gelände die Riesensteine und Ablagerungen, das «terrain erratique», zeigen. Dabei erging es ihm seltsam. Er wurde von Venetz als erster Anhänger gewonnen.

Nachdem die ursprüngliche Abhandlung von Venetz mit Zusätzen 1833 erschienen war, meldete sich Charpentier an der Versammlung der Schweizer Naturforscher 1834 in Luzern zum Wort. Er las das Mémoire: «Annonce d'un des principaux résultats des recherches de Mr. Venetz, ingénieur des Ponts et chaussées du Canton du Vallais, sur l'état actuel et passé des Glaciers du Vallais », wie das Protokoll angibt. Diese Anzeige eines Hauptergebnisses der Untersuchungen des Ingenieurs Venetz betraf die Verfrachtung der Findlinge. Nach der Prüfung ihrer kantigen Gestalt habe Venetz dargelegt, daß nicht das Wasser sie dahingerollt habe. «Herr Venetz war der Erste, welcher annahm, diese Felsblöcke seien durch Gletscher in die Thäler herabgestoßen worden, als Theil jenes morastigen Schuttes, der an den untern Gletscherrändern sich findet.» Charpentier unterstützte diese Behauptung durch neue Gründe. Als jemand den Einwand erhob, es gebe doch versteinerte Palmstämme und müsse daher früher wärmer gewesen sein, erwiderte Charpentier unverweilt, die Alpenerhebung habe sich später als damals vollzogen und sei einst viel beträchtlicher gewesen. Auf warme seien kalte Zeiten mit ausgedehnten Gletschern gefolgt.

Im jungen Louis Agassiz wurde die Aufmerksamkeit geweckt. 1836 kam er sechs Wochen in die Nähe von Charpentier. Als Präsident der Jahresversammlung von 1837 in Neuenburg behandelte er den Gegenstand im Eröffnungsvortrag. Von der Glazialtheorie, wie Venetz und Charpentier sie verstanden, hatte er sich noch nicht überzeugen lassen; denn er nahm an, daß die Gletscher schon vor der Bildung der Alpen, von der Polargegend herkommend, dagewesen seien. Als die Berge sich aufwölbten und aus dem Eise hervorstießen, seien die Findlingsblöcke auf der geneigten Fläche von den Alpen zum Jura geglitten. Dolomieu (1750-1801), Geologe in Paris, und EвEL hatten früher in ähnlicher Weise eine geneigte Erdfläche angenommen.

1839 kehrte Agassiz mit seinem Freunde Edouard Desor (1811-1882) ins Wallis zurück. Auch Bernhard Studer war dabei, als sie in Zermatt eine fünftägige Exkursion unternahmen. Der Gornergletscher war damals im Wachsen begriffen und begrub die Weiden von Aroleit. Der Anblick beeindruckte die Beobachter tief.

Während Venetz und Charpentier sich mit der Struktur des Gletschers 
und dem Mechanismus seiner Bewegung nicht eingehender beschäftigt hatten, stellten sich Agassiz und Desor gerade diese Aufgabe. Von 1840 bis 1846 führten sie mehrere Aufenthalte auf dem Unteraargletscher durch. Sie bohrten ein $45 \mathrm{~m}$ tiefes Loch, maßen Temperaturen, untersuchten den Schichtenbau des Eises, unternahmen Färbversuche, um das Eindringen des Wassers zu prüfen, und zeichneten eine Karte. Agassiz veröffentlichte 1840, Charpentier 1841, Desor 1845 ein Buch.

Agassiz widmete seine Studien Venetz und Charpentier: «Ihre wichtigen Arbeiten haben mich angespornt, die Gletscher unserer Alpen zu untersuchen; Ihrer Güte verdanke ich die freundschaftlichen Anleitungen, welche mich in den Stand setzten, selbständig mit Nutzen diesen Gegenstand zu verfolgen.» In einer Anmerkung (auf S.13) bezeugt er, daß frühere Ansätze zu einer Glazialtheorie vergessen waren, «bis Venetz durch zahlreiche Beobachtungen und unwiderlegliche Tatsachen ihnen eine wissenschaftliche Begründung verlieh».

Charpentiers Essai sur les glaciers stellte sich in den Dienst der Ansichten von Venetz und gab ihnen Durchschlagskraft. «Es ist gewissermaßen Venetz, dem ich die besondere Beschäftigung mit dem erratischen Gelände verdanke. Er hat mir darin große Hilfe geboten. Zudem ist Venetz der erste, der mit unbestreitbaren Tatsachen bewiesen hat, daß die Gletscher des Wallis und der angrenzenden Länder einst eine beträchtlichere Entwicklung hatten als heute.»

Während das Gut seines Geistes sich ausbreitete, kämpfte Venetz beharrlich, um die Bucht von Clarens den Überflutungen abzuringen. Er konnte nicht mehr forschen und schreiben; er mußte hacken und schaufeln. Als nach Jahren und Jahren das Unterfangen gescheitert, er davon befreit und erlöst war und sich mit den Trümmern seiner Habe ins Wallis zurückgerettet hatte, durfte er aufatmen. Und nun erleben wir das Wunder, daß der Greis nach den unsäglich schweren Mühsalen noch nicht gebrochen war. Jetzt, gegen Ende des Lebens, immer noch berufstätig, war es ihm in spärlicher Freizeit gegönnt, eine zweite Abhandlung über die Ausdehnung der frühern Gletscher zu vollenden. Sie konnte 1861 nach seinem Tode in den Denkschriften der Schweizerischen Naturforschenden Gesellschaft erscheinen und wurde mit freundlichen Zeilen eingeleitet.

Venetz zitiert hier Charpentiers Beschreibung des großen Findlings, der auf der Anhöhe von Valeria bei Sitten am Rand eines felsigen Abgrundes liegt. Er ruht auf vier Punkten : das eine ist ein kleiner kristallinischer Block; das zweite und dritte sind Bruchstücke, die sich vom Felsen der Unterlage 
abgespalten haben; das vierte ist der Findling selber. Er besteht aus Kalk, besitzt über $3 \mathrm{~m}$ Durchmesser und ist von oben bis unten gespalten. Venetz erklärt, wie diese Erscheinungen entstanden sein könnten.

Der Rhonegletscher trug den Findling heran und stieß auf das Hindernis des Felshügels. Ähnlich, wie der Fieschergletscher sich gegen sein unteres Ende an einem Felssporne hebt und in zwei Teile spaltet, habe sich der Rhonegletscher wohl am Felsen von Valeria aufgerichtet und zerspalten. Der kleine kristallinische Block fiel zuerst in die Spalte; der größere Kalkblock folgte. Die Heftigkeit seines Aufpralls trennte zwei Bruchstücke vom Felsgrund los und brach den Stürzenden selber entzwei.

Venetz schreibt, bis 1829 habe er Zeugnisse für die größte Ausdehnung der alten Gletscher gesucht und sie bis zum Jura gefunden. Bei weitern Beobachtungen habe sich als neue Frage die nach der Mehrzahl glazialer Entfaltungen gestellt. Davon spricht der zweite Teil seiner Darstellung.

Im Jura sah er einzelne Blöcke aus Alpengestein, die zuoberst auf den Höhen lagen, ferner lange Moränen an den Randketten vom Neuenburgerbis Genfersee: am Chasseron, Suchet und Mont Tendre. Es sind die Zeugen zweier Eiszeiten, Riß und Würm, wie Albrecht Penck und Eduard BrüCKNer 1909 festlegten. Venetz betrachtete sie als Ablagerungen derselben Epoche.

Als zweiten Zeitabschnitt betrachtete er den, wo der Rhonegletscher noch die Becken des Genfer- und Neuenburgersees eingenommen hatte. Spuren jener Vergangenheit sah Venetz bei den hoch über Bex und Aigle gelegenen Waadtländer Dörfern Gryon, Huémoz, Corbeyrier, ferner bei Lausanne, wo die Straße von Bourg auf einer Moräne verläuft, die sich westwärts bis Ecublens ausdehnt. Einen dritten Vorstoß des Rhonegletschers nahm Venetz bis nahe an das obere Ende des Genfersees an. Ihm schrieb er die Seitenmoränen unter Yvorne bei Aigle zu, die Granitblöcke auf dem Hügel von St-Triphon und auf der Anhöhe des Montet bei Bex. Auf der andern, der Walliser Seite des Flusses seien die Spuren ebenfalls zahlreich: die Moräne von Monthey, die von Ravoire über Martigny, jene im Entremonttale bei Orsières und jene westlich davon am Lac de Champex. Die Vorstöße der vierten, weniger weit zurückliegenden Epoche hätten in allen Seitentälern des Wallis viele Moränen hinterlassen. Der Rhonegletscher sei bis Obergestelen gekommen; der von Fiesch habe den prächtigen Wall von Geröll unter Bellwald aufgeschüttet. Die GJetscher von Saas hätten Blöcke von Gabbro und Serpentin gegen Grund getragen. Trient, das Dorf im Trient -Tal bei Martigny, stehe auf einer Endmoräne des Trientgletschers. «Im Wallis 
müssen diese Moränenanhäufungen den von den Gletschern erlittenen Schwankungen zugeschrieben werden ", bemerkte Venetz. Darin lag die Ahnung der Wahrheit. Die Moränen und Blöcke, die er vier glazialen Vorstößen zuordnete, wurden nach der seitherigen Deutung während der Würmeiszeit abgelagert und bezeichnen Rückzugsstadien, zum Beispiel Bühl in Monthey, Gschnitz in Orsières, Daun in Obergestelen.

Der dritte Teil der Abhandlung bespricht Arbeiten dreier Forscher. Charles-Frédéric Martins (1806-1889), Professor in Montpellier, und Bartolomeo Gastaldi (1818-1879), Professor der Geologie an der Ingenieurschule Turin, hatten als frühe Anhänger seiner Glazialtheorie die Ablagerungen der Poebene erforscht, und Edouard Desor hatte die Untersuchungen auf Nordeuropa und Amerika ausgedehnt.

So durfte Venetz noch erleben, daß seine Lehre sich auszubreiten begann. Zuerst hatten nur Bergbewohner in ihrer Umgebung wahrgenommen, wie die Gletscher den Schutt und die Felsbrocken trugen. Ein Feldhüter und Gemsjäger in Lourtier im Bagnes-Tal, Jean-Pierre Perraudin (1767 bis 1858), hat als erster geahnt, daß sein Tal einst von einem Gletscher erfüllt gewesen sei. Bei Venetz und Charpentier wird die Vermutung zur Wissenschaft. Sie gewinnt von der Schweiz aus Frankreich, Italien, Nordeuropa, England, Rußland, Nordamerika, Asien und beschäftigt Geschlechter von Geomorphologen bis heute.

\section{Venetz als Botaniker und Entomologe}

Schon als junger Ingenieur widmete Venetz sich den Naturwissenschaften, und diese Liebe hat ihn durch sein Leben begleitet. Auf seine beruflichen Gänge nahm er den Geologenhammer und die Botanisierbüchse mit. Bereits 1817 verfaßte er einen Katalog der im Wallis wildwachsenden Pflanzen.

Förderung erfuhr diese Neigung durch seine Freundschaft mit Jean de Charpentier, der damals vor allem Schnecken sammelte und auch andere dazu anleitete. Am 1.Februar 1820 schrieb Charpentier an KARL Friedrich Meisner (Vater), den Professor für Naturgeschichte in Bern und Herausgeber des Naturwissenschaftlichen Anzeigers: «Meine Sammlung ist jetzt schon ziemlich ansehnlich; ich habe 256 Arten und 613 Abarten oder Varietäten. Kürzlich habe ich endlich vom guten Venetz einen sehr schönen Helix pomatia ocularis erhalten welcher lebendig bey Monthey im Wallis, 
Bex gegenüber, gefunden worden ist.»Venetz war also ein guter Beobachter, der sogar fand, was Charpentier lange vergeblich gesucht hatte.

Bei der Jahresversammlung der Schweizerischen Naturforschenden Gesellschaft vom Sommer 1822 in Bern weilten die beiden in Meisners Hause, wo sie Güte und Freundschaft genossen und OKen kennenlernten ${ }^{2}$.

Gemeinsam kehrten Charpentier und Venetz von Bern zu Fuß ins Wallis zurück. Charpentier berichtete darüber am 23. August 1822 an Meisner: «Wir kamen [am Donnerstag] gegen Mittag in Thun an wo wir den Herrn Kasthofer fanden und von unserm teutschen Professor [Oken], seiner Gemahlin, und seinen beyden uner- und unge-zogenen Kindern [einem Knaben und einem Mädchen] eingeholt wurden. Wir benutzten gemeinschaftlich ein retour-Schiff bis Unterseen und nahmen von da eins nach Brienz wo wir zusammen die Nacht zubrachten. Am. Freytag Morgens gieng ich mit Venetz vor Ockens noch nach Meyringen ab, wurde aber, da diese einen Wagen in Brienz genommen hatten, von ihnen beym Frühstück in Meyringen abermals eingeholt. Hier trennten wir uns gänzlich indem Ockens über die Scheideg nach Grindelwald, Venetz und ich aber nach der Grimsel gingen, wo wir Abends bey starkem Regen ankamen. Am Sonnabend giengen wir geognisando herborisando und desinando bis Lax; am Sonntag früh ins Binnerthal wo wir 2 halbe und einen ganzen Tag blieben während welcher Zeit ich die geognostische Karte dieses Thals aufgenommen habe die wirklich recht leidlich gerathen ist. Von da giengen wir über die Berge ins Ganderthal [Gantertal] nach Brieg, wo Venetz blieb, ich aber meinen Weg über Sitten und Evionnaz bis Bex fortsetzte.» Charpentier schreibt weiter, in geognostischer Hinsicht sei ihm die Wanderung nützlich gewesen. In der Gegend um Winkel und Im Grund ob Meiringen sehe man deutlich die Auflagerung des neuern Übergangsgebirges auf das ältere. Das Gadmental und wahrscheinlich auch das Urbachtal seien auf der Ablösung beider Gebirgsformationen eingegraben. Auf der Grimsel habe er die seltene Seggenart Carex approximata noch in gutem Zustand sammeln können. Auch erkundigt er sich: «Wie wird es denn mit dem Druck des Venetzischen memoires werden? Gut würde es seyn wenn man mir es zuschickte damit Venetz hier

2 Lonenz OKen, 1779-1851, Herausgeber der Zeitschrift Iris, hatte seine Medizinprofessur in Jena verloren und einen Winter in Basel Vorlesungen gehalten. Bevor er nach Jena zurückkehrte, besuchte er die Tagung in Bern und gründete anschließend entsprechende Jahresversammlungen der Naturforscher und Ärzte in Deutschland, deren erste 1822 in Leipzig stattfand. 1833 folgte er einem Rufe an die neugegründete Universität Zürich und lehrte dort unter hoher Anerkennung Naturgeschichte. 
bey mir einige wesentliche Correctionen und Zusätze machen könnte. Haben Sie doch die Güte deswegen mit dem Herrn Haller zu sprechen.» (Gemeint ist wohl Buchdrucker Albrecht Haller in Bern, 1773-1837, ein Großneffe des Gelehrten.)

Als Sammler entdeckte Venetz manche seltene Pflanze, besonders am Südhang des Simplons und in den beiden gleichlaufenden Tälern von Zwischbergen und Laquin. Der Katalog der Walliser Pflanzen seines Herbariums erschien im Druck. Auch konnte er einen guten Jünger in die Botanik einführen, Alphonse Rion, Naturgeschichtslehrer und Domherrn in Sitten, der zum Dank die zierlich gefiederte Erdrauchpflanze Fumaria Venetzii nach ihm benannt hat.

Die reichen Insektensammlungen von Venetz gelangten an seinen Sohn Franz. Nach dessen Tode wurden sie von der Regierung des Kantons Waadt gekauft und bildeten eine Zierde des Kantonalmuseums in Lausanne.

\section{Die letzten Jahre}

Als waadtländischer Kantonsingenieur hatte Venetz die Beziehung zur Heimat aufrechterhalten. 1840 bis 1842 war er mit Untersuchungen beauftragt, wie man die Straße über den Großen St.Bernhard fahrbar gestalten könnte, vor allem den obersten Abschnitt zwischen der Schenke von Proz und dem Hospiz. 1851 begann ein sardinischer Unternehmer, einen Tunnel unter dem $P a ß$ hindurch zu bauen, und Venetz hatte sich mit der Führung der Straße von Proz bis zum Tunneleingang zu beschäftigen. Er legte mehrere Pläne vor. Da aber im Winter alles zugeschneit war, gab man diese Arbeiten wieder auf. Die Erwartung wandte sich dem Simplon zu.

Eine französische Vereinigung wollte die Eisenbahn, die von Genf her südlich des Genfersees bis an sein oberes Ende gelangte, durch das Rhonetal aufwärts führen. Sie dachte für die fernere Zukunft an eine Fortsetzung durch den Simplon und nannte sich daher «Eisenbahngesellschaft der Linie nach Italien ». Nachdem sie die Erlaubnis erlangt hatte, begann sie mit dem Bahnbau im untersten Abschnitt des Wallis. Vater und Sohn Venetz konnten sich von 1856 bis 1858 als Ingenieure gemeinsam daran beteiligen. Beide erhielten monatlich je 400 Franken. Das Einkommen enthob Venetz der Sorgen, die ihn lang begleitet hatten. Die freie Zeit widmete er der Abfassung seiner zweiten Denkschrift über die Ausdehnung der frühern Gletscher. Die Eröffnung der Bahn erlebte èr nicht mehr; das Teilstück Le 


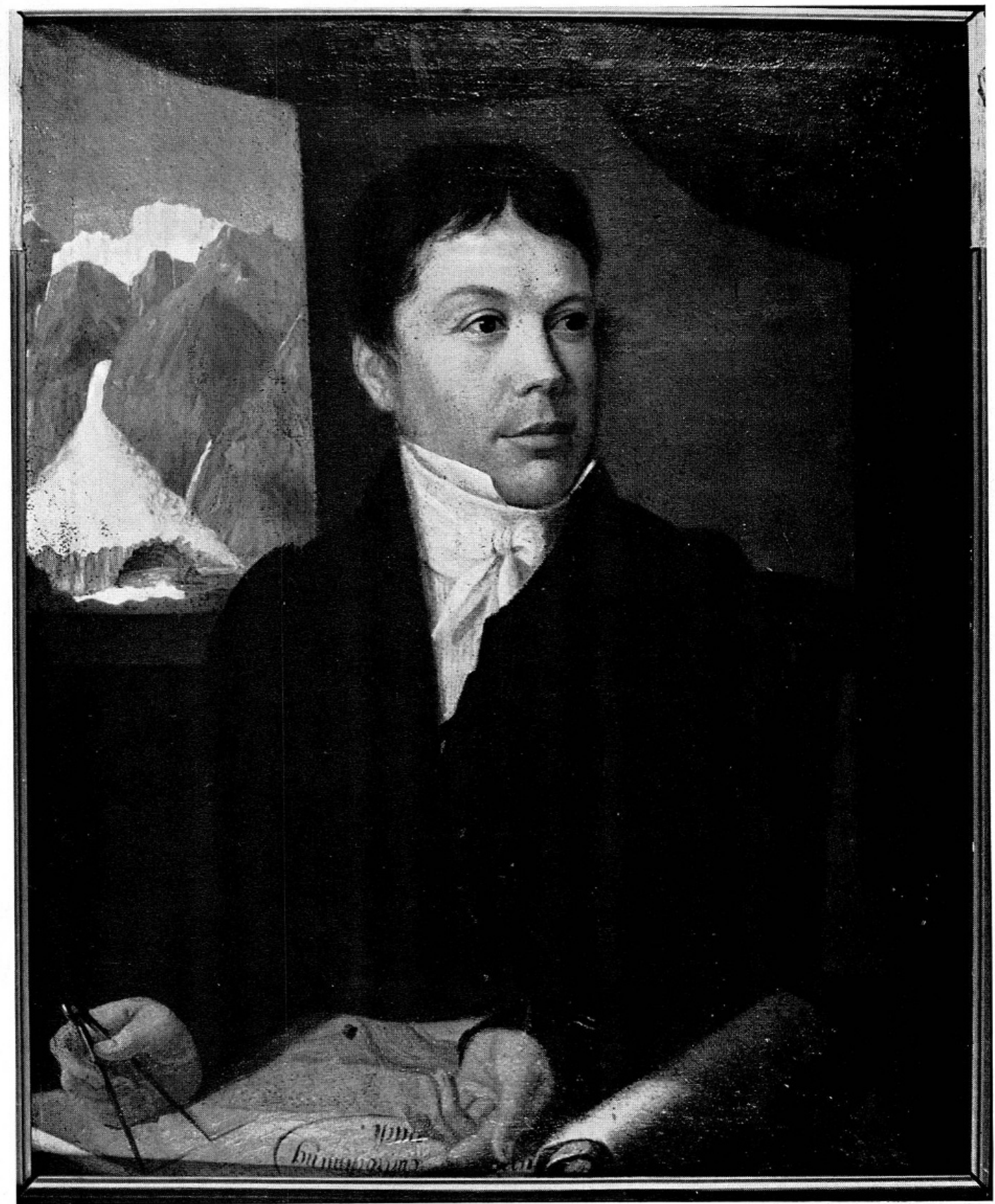

Abb. 1. Ignaz Venetz (38jährig, 1826).

Gemälde von Laurent -Justin Ritz. Im Museum von Majoria, Sitten 


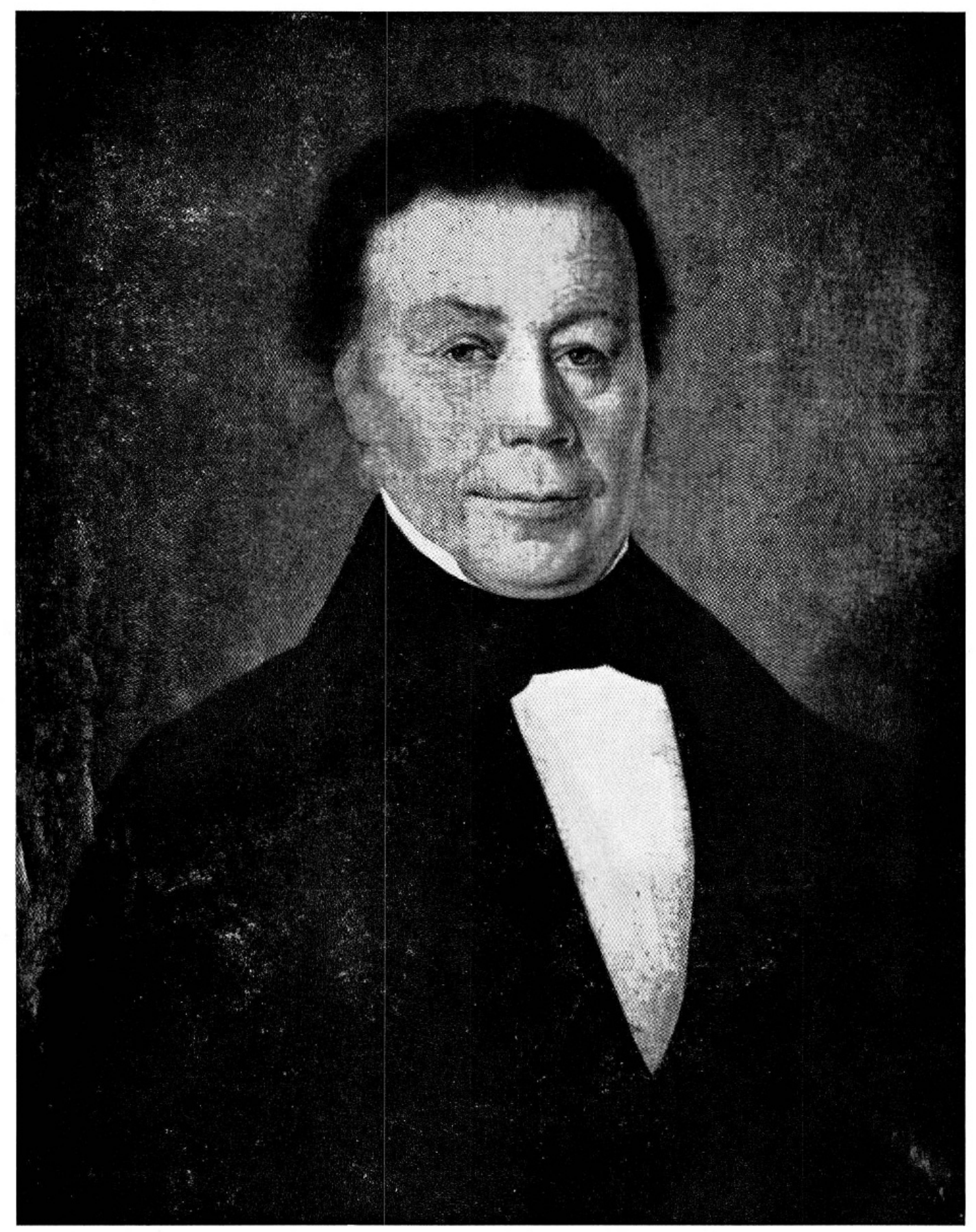

Abb. 2. Ignaz Venetz (66jährig, 1854).

Gemälde von Laurent -Justin Ritz. Im Museum von Valeria, Sitten 


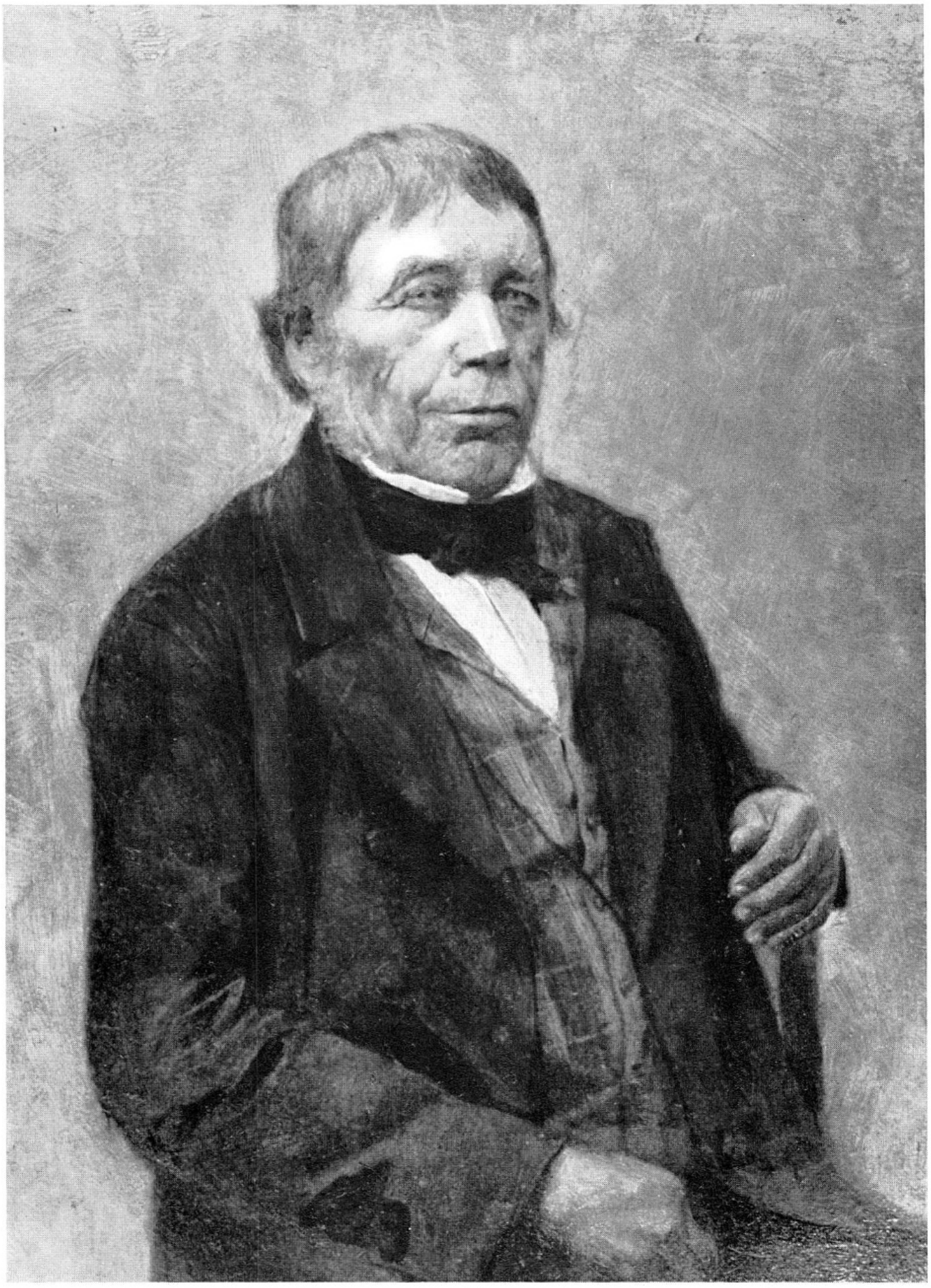

Abb.3. Ignaz Venetz. Altersbildnis im Besitz des Naturhistorischen Museums Bern 
Bouveret-Martigny wurde am 1. Juli 1859 eingeweiht, und im Mai 1860 wurde die Verlängerung bis Sitten fertig.

1858 beschlossen die Gemeinden Riddes und Saxon, die zwischen Sitten und Martigny im Rhonetal liegen, ihre sumpfige Ebene trockenzulegen, und zwar wollten sie künstliche Ablagerungen aus der Rhone vornehmen lassen, damit der Boden sich erhöhe. Als Fachmann wurde Venetz beigezogen. Er beging im Februar 1859 jene Sümpfe und entwarf den Plan für die Arbeit. Dabei erkältete er sich. Eine Lungenentzündung warf den 71 jährigen nieder, und an ihren Folgen starb er am 20. April 1859, morgens zwei Uhr, in Sitten.

Das Wallis trauerte um ihn. Sein Werk hatte dem Gemeinwohl gegolten. Für viele Gemeinden hatte er Wuhrbauten ausgeführt. Visp besitzt einen Venetzkanal. Er hatte Straßen mitgeplant, so über die Furka.

In der Waadt hinterließ Venetz gleichfalls ein dankbares Andenken, wie der Nouvelliste Vaudois bekundete. Auch dort hatte sich sein Name ehrenvoll mit Unternehmungen öffentlichen Nutzens verbunden.

Dem Wallis hinterließ er den besten Ingenieur in seinem Sohne Franz (1821-1870). Franz war mit Joséphine Calpini verheiratet und starb mit 49 Jahren kinderlos. Seine Frau, die ihn lange überlebte, leitete die Mädchennormalschule von Sitten.

Während der Name Venetz mit ihr unter den Nachkommen erlosch, setzte ein Bruder des Ignaz an der neuen Brücke bei Stalden den Stamm bis heute fort. Die Familie betrieb die dortige Mühle.

Was Ignaz Venetz über die Zeit hinaushob, war seine Begründung der Glazialtheorie. Die Sektion Monte Rosa des Schweizer Alpen-Clubs ehrte ihn durch eine Gedenkstätte. Auf der Höhe von Valeria hinter Sitten liegt jener große Findling, dessen Lage Venetz erläutert hatte. Dort wurde die Inschrift «I. Venetz 1821 » eingehauen. Am 20. November 1868 abends hielt man im Beisein des Sohnes eine schlichte Einweihungsfeier, die der Walliser Staatsmann und Dichter Leo Luzian von Roten beschrieben hat. Als der Schweizer Alpen-Club 1874 in Sitten tagte, bot Ferdinand Otto Wolf einen Vortrag über vier Walliser Naturforscher. Darin stand Venetz neben drei Priestern. Es waren der Botaniker Laurent -Joseph Murith (1742 bis 1816), der Geodät Joseph Anton Berchtold (1780-1859) und der Botaniker Alphonse Rion (1809-1856).

Ignaz Venetz geht als echtes Kind des Wallis in die Geschichte ein. Er war ein naturnaher Bergler, ein Augenmensch, ein beharrlicher Beobachter. Großes und Kleines zog ihn an, die Gletscher, Flüsse und Felsen, die Pflan- 
zen, Insekten und Schaltiere. So blieb er nicht ein Praktiker. Aus seinen beruflichen Pflichten erwuchsen ihm Fragen der Wissenschaft, die ihn begleiteten und denen er mit dem reinen Drang nach Erkenntnis selbstlos diente. Darum neigen wir uns vor ihm. 


\section{Schriftum}

\section{Abhandlungen von Ignaz Venetz}

1820 Relation de l'éboulement du glacier du Weisshorn arrivé le 27 décembre 1819 et de la destruction du village de Randa. Naturwissenschaftlicher Anzeiger, Bern

1826 Apologie des travaux du glacier de Giétroz, contre les attaques réitérées du chanoine Blanc, Sion (23 S.)

1833 Mémoire sur les variations de la température dans les Alpes suisses, rédigé en 1821, publié en 1833 (in den Denkschriften der Schweizerischen Naturforschenden Gesellschaft)

1843 Note sur le glacier du Giétroz. Actes de la Société Helvétique des Sciences Naturelles, Lausanne, S. 109-117. Siehe auch S. 54, 76, 78

1852 Mémoire sur les digues insubmersibles, sur les écluses à cheminées pour le colmatage et sur les principes à suivre dans les corrections des cours d'eau, avec leur application spéciale aux redressements de l'Orbe et de la Broye et à l'assainissement des marais adjacents. Bibliothèque universelle, Genève

1859 Note sur le glacier diluvien de la vallée du Rhône. Bulletin de la Société Vaudoise des Sciences Naturelles

1861 Mémoire sur l'extension des anciens glaciers, renfermant quelques explications sur leurs effets remarquables. Nouveaux mémoires de la Sociêté Helvétique des Sciences Naturelles, Vol. XVIII, Zurich, S. 1-23

Ungedruckt: 1820/27/28: Rapport sur le lac de Märjelen. Archives cantonales de Sion, Signatur III $5 / 53$

\section{Nachrichten über Arbeiten von Venetz}

a) Zu den Vorkehrungen am Giétroz-Gletscher (nach Angaben von Ignace Mariétan)

Ungedruckt: Archives cantonales de Sion, Département des Travaux publics, Dossier de Giétroz

Philippe Bridel, Course à l'éboulement du glacier de Giétroz et au lac de Mauvoisin, 16 mai 1816, Vevey

Philippe Bridel, Seconde course dans la vallée de Bagnes et détails sur les ravages occasionnés par l'éboulement du lac de Mauvoisin, 21 juin 1818, Vevey

Hans Conrad Escher de la Linth, Notice sur le Val de Bagnes en Bas-Valais et sur la catastrophe qui en a dévasté le fond en juin 1818. Bibliothèque universelle, Genève 1818

Hans Conrad Escher de la Linth, Friedrich Trechsel, Jean de Charpentier, Rapport sur l'état actuel de la vallée de Bagnes dans le canton du Valais relativement aux mesures propres à la prémunir contre l'effet destructeur du glacier inférieur de Giétroz, Zurich 1821 (59 S.) Notice sur les travaux exécutés au glacier de Giétroz par Venetz après la débâcle. Bibliothèque universelle, tome $25,1824, \mathrm{~S} .240-243$ 
JeAn-Joseph Blanc, Observations sur les travaux que le gouvernement du Valais fait exécuter au glacier de Giétroz, vallée de Bagnes, dans le dessein de prévenir une nouvelle débâcle, Lausanne 1825 (24S.)

Dr. Leo Hallenbarter sah 1935 die Streitschriften über die Schutzmaßnahmen am GiétrozGletscher im Museum des Geschichtsforschenden Vereins vom Oberwallis in Brig.

Ungedruckt： Briefe Jean de Charpentiers an Karl Friedrich Meisner (Vater) vom 17. Juni und 12.September 1818 und 11. Juli 1820. Universitätsbibliothek Basel, Handschriftenabteilung

b) $\mathrm{Zu}$ andern Tätigkeiten von Venetz als Ingenieur

Отто Lütschg, Der Märjelensee und seine Abflußverhältnisse, Bern 1915

Отто Lüтschg, Über Niederschlag und Abflu $\beta$ im Hochgebirge. Sonderdarstellung des Mattmarkgebietes, Zürich 1926

Ignace Mariétan, La lutte contre l'eau en Valais. Actes de la Société Helvétique des Sciences Naturelles, Sion 1942, S.1-26

Mémorial des travaux du canton de Vaud, Lausanne 1896

Ungedruckt： Briefe Jean de Charpentiers an Karl Friedrich Meißner (Sohn) vom 15. März 1847 und 17.Februar 1849. Universitätsbibliothek Basel, Handschriftenabteilung. (Der Vater schrieb sich Meisner, der Sohn Meißner)

c) Zur Gletschertheorie (zeitlich geordnet)

Actes de la Société Helvétique des Sciences Naturelles. Quinzième réunion annuelle, à l'hospice du Grand-Saint-Bernard, les 21, 22 et 23 juillet 1829, S. 31 (zum Vortrag von Venetz). Siehe dort auch S. 35

Verhandlungen der allgemeinen schweizerischen Gesellschaft für die gesammten Naturwissenschaften, Luzern, 28., 29. und 30. Juli 1834, S.23f. (zum Vortrag von Charpentier)

Louis Agassiz, Etudes sur les glaciers, Neuchâtel 1840. Deutsche Ausgabe: Untersuchungen über die Gletscher, Solothurn 1841. (Venetz und Charpentier gewidmet)

Jean de Charpentier, Essai sur les glaciers et le terrain erratique du bassin du Rhône, Lausanne 1841 (363 S.)

Johann JaKob Siegrried, Geschichtliche Notizen über die Gletschertheorie. Jahrbuch des S.A.C., Band X

Albert Heim, Handbuch der Gletscherkunde, Stuttgart 1895, S. 534f.

Françors-Alphonse Forel, Perraudin, le précurseur glaciairiste. Eclogae Geologicae Helvetiae VI, 1899

Henri Onde, Observations glaciologiques en Suisse et en Savoie, il y a un siècle. Revue de la Géographie alpine, tome 36, 1948, S. 399-409 


\section{Gesamtwürdigungen}

a) Reichste und zuverlässigste Quelle, aus der ich viel geschöpft habe:

Ignace Mariétan, La vie et l'œuvre de l'ingénieur Ignace Venetz (1788-1859). Bulletin de la Murithienne (Société Valaisanne des Sciences Naturelles) 1959, S.1-51. - Daraus sind die S. 35-45 ("Venetz et la théorie glaciaire») auch abgedruckt in: Die Alpen, 1961, S.56-65. (Beidemal mit dem Jugendbildnis von Venetz)

b) Frühere Berichte (zeitlich geordnet):

Gazette du Valais 1859

Leo Luzian von Roten, Das Venetz-Denkmal bei Sitten. Jahrbuch des S. A. C., Band VI Ferdinand Otтo Wolf, Biographische Notizen über die Walliser Naturforscher Murith, Venetz, Berchtold und Rion, S. 8-34 in: La onzième Réunion annuelle du Club Alpin Suisse à Sion (1874). Venetz: S. 17-21

Emile Burnat, Ignace Venetz, ingénieur. Bulletin de la Murithienne 37, 1911

Maurice Besse, Les Naturalistes Valaisans. Eröffnungsrede des Jahrespräsidenten. Actes de la Société Helvétique des Sciences Naturelles, Zermatt 1923. Venetz: S. 24-26

La vie romantique au pays romand, Lausanne 1930

Leo Hallenbarter, Ignace Venetz. Walliser Jahrbuch 4 (1935), S. 73-77 (mit 3 Abbildungen : Bildnis von 1854, Geburtshaus, Venetz-Denkmal auf Valeria)

300 Jahre Kollegium Brig (1662/63-1962/63). Festschrift 1963. Venetz: S. 99 (mit seinem Jugendbildnis)

Ungedruckt： JosePh Bürcher, Ignaz Venetz, 1788-1859. 8 S. Maschinenschrift, 1968 (bei mir)

Wie Hallenbarter mitteilt, gibt es einen Stammbaum der Familie Venetz. 1935 war er im Besitz der Familie Kamill Noti in Stalden. 


\section{Zu den Bildnissen}

1. Jugendbild von 1826 , gemalt von Laurent-Justin Ritz. Öl auf Leinwand, $53 \times 44,5 \mathrm{~cm}$. Im Museum von Majoria (Musée de la Majorie), Sitten. (Dort auch das Bildnis seiner Frau.)

Beste Wiedergabe in: Albert de WolfF, Le portrait Valaisan, Genève 1957, S. $255^{3}$.

2. Altersbild von 1854, gemalt von LAURENT -Justin Ritz. Öl auf Leinwand, $58 \times 47,5 \mathrm{~cm}$, hinten signiert, datiert und numeriert: No 586. Seit 1959 im Museum von Valeria (Musée de la Valérie), Sitten. Abgebildet in Vallesia XV, 1960, Tafel II, beschrieben S. XIV.

3. Das andere Altersbildnis fand ich 1967 in einer Estrichkammer des Naturhistorischen Museums in Bern, wozu mir Dr. Hans Adrian den Zugang öffnete.

Laurent-Justin Ritz (1796-1870), Walliser Maler, ausgebildet in Einsiedeln, Genf, Willisau, München und Wien, Zeichenlehrer an den Kollegien in Brig und Sitten, schuf Bildnisse, Kirchengemälde und Ortsansichten. Albert de Wolff, Le portrait Valaisan, Genève 1957, würdigt Ritz S. 8 und gibt S. 32 einen Stammbaum seiner Familie. Er war Vater des Malers Raphael Ritz (1829-1894) und Großvater des Physikers und Mathematikers WaLther Ritz (1878-1909). Die Selbstbiographie von Laurent-Justin Ritz, «Notizen aus meinem Leben", wurde von ANTon GatTLEN in Vallesia 1961 herausgegeben ${ }^{4}$. Ritz pflegte seine Porträts hinten zu numerieren und in ein Porträtverzeichnis einzutragen. Dieses veröffentlichte Gattlen in Vallesia 1963. Wir lesen darin:

1824, Nr.165, Mad. Ingenieur Venetz in Sitten, 16 Fr.

1826, Nr.186, Hr. Ingenieur Venetz, von Sitten, in Brig, 16 Fr.

1841, Nr.423, Mlle Josette Venetz, von Sitten, 12 Fr.

1854, Nr.586, Hr. Venetz, Ingenieur und Gelehrter, von und in Sitten, 30 Fr.

Mad.Venetz ist die 1791 geborene Frau, Josette die 1815 geborene Tochter des Ignaz.

${ }^{3}$ In diesem Werke finden sich auch die Bildnisse des Schwiegervaters und des Gegenschwähers von Venetz, nämlich auf S. 263 JEAN -JosePh ANDENMATten (1754-1829), gemalt von Antoine Hecht, und auf S.279 Jacques CalPiNi (1804-1870). Andenmatten war Architekt in Sitten, baute sich 1786 bei der großen Brücke ein Haus, errichtete nach dem Stadtbrand von 1788 viele Häuser neu, schuf 1806-1809 die Kirche des Jesuitenkollegiums Sitten und 1809-1812 die besonders schöne Kirche seines Geburtsortes SaasBalen. - Calpini, Sohn eines 1797 aus Vanzone im Eschental eingewanderten Kaufmanns, der 1816 das Bürgerrecht von Sitten erwarb, wurde Gemeinderat, Vizestadtpräsident und Hauptmann; seine Tochter heiratete Franz Venetz.

4 Darin taucht Venetz nicht auf, wohl aber Charpentier. Ritz berichtet, wie er und sein Sohn am 21.Oktober 1849 in Sitten Dr. (Ferdinand) Keller von Zürich kennenlernten (den Archäologen, 1800-1881). «Mit ihm machte Raphael noch ein Reischen bis Vivis [Vevey], bei welcher Gelegenheit Raphael auch den Herrn Dir. der Salzminen von Bex, den gelehrten Herrn von Charpentier, kennen lernte, welcher dem lernbegierigen Knaben auch auf spätere Zeiten seine Freundschaft versprochen hat.» 